\title{
A systematic review and meta-analysis on the effectiveness of xenograft to prevent periodontal defects after mandibular third molar extraction
}

\author{
Jorge Toledano-Serrabona ${ }^{1}$, Víctor Ruiz-Romero ${ }^{2}$, Octavi Camps-Font ${ }^{3}$, Cosme Gay-Escoda ${ }^{4}, \mathrm{M}^{\mathrm{a}}$ Ángeles \\ Sánchez-Garcés ${ }^{5}$
}

${ }^{1}$ DDS. Fellow of the Master's degree programme in Oral Surgery and Implantology, Faculty of Medicine and Health Sciences, Dental School, University of Barcelona. Researcher at IDIBELL (Bellvitge Biomedical Research Institute), Barcelona, Spain

${ }^{2}$ Dental student. Faculty of Medicine and Health Sciences, Dental School, University of Barcelona, Spain

${ }^{3}$ DDS, MS. Associate Professor of Oral Surgery. Master's degree programme in Oral Surgery and Implantology, Faculty of Medicine and Health Sciences, Dental School, University of Barcelona. Researcher at IDIBELL (Bellvitge Biomedical Research Institute), Barcelona, Spain

${ }^{4}$ MD, DDS, MS, PhD, EBOS, OMFS. Chairman and Professor of Oral and Maxillofacial Surgery, Faculty of Medicine and Health Sciences, Dental School, University of Barcelona. Director of the Master's degree programme in Oral Surgery and Implantology (EFHRE International University/FUCSO). Coordinator/Researcher at IDIBELL (Bellvitge Biomedical Research Institute). Head of the Oral Surgery, Implantology and Maxillofacial Surgery Department at the Teknon Medical Centre, Barcelona, Spain ${ }^{5}$ MD, DDS, MS, PhD, EBOS. Lecturer in Oral Surgery. Master's degree programme in Oral Surgery and Implantology, Faculty of Medicine and Health Sciences, Dental School, University of Barcelona. Researcher at IDIBELL (Bellvitge Biomedical Research Institute), Barcelona, Spain

Correspondence:

School of Medicine and Health Sciences. Dental School

Campus de Bellvitge, University of Barcelona

C/ Feixa Llarga, s/n; Pavelló Govern $2^{a}$ planta, Despatx 2.9

08907 L'Hospitalet de Llobregat; Barcelona, Spain

ocamps@ub.edu

Toledano-Serrabona J, Ruiz-Romero V, Camps-Font O, Gay-Escoda C, Sánchez-Garcés MÁ. A systematic review and meta-analysis on the effectiveness of xenograft to prevent periodontal defects after mandibular third molar extraction. Med Oral Patol Oral Cir Bucal. 2021 Jul 1;26 (4):e414-21.

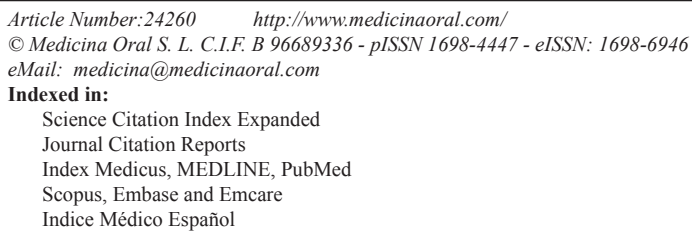

\begin{abstract}
Background: To evaluate the use of guided bone regeneration with xenograft to prevent periodontal defect in the distal aspect of the second molar after the surgical removal of the mandibular third molar.

Material and Methods: Three electronic databases (Pubmed, Cochrane Library and Scopus) were searched in April 2020. Randomized clinical trials in non-smokers and healthy patients, with at least six months followup, comparing periodontal probing depth, clinical attachment level, alveolar bone level and adverse events were selected by two independent investigators. The risk of bias assessment of the selected studies was evaluated by means of the Cochrane Collaboration's Tool. Finally, a meta-analysis of the outcomes of interest was performed. Results: Despite 795 articles were found in the initial search, only three randomized controlled clinical trials were included. Pooled results favoured the use of the xenograft plus collagen membrane over the spontaneous healing in terms of periodontal probing depth gain $(\mathrm{MD}=2.36 ; 95 \% \mathrm{CI} 0.69$ to $4.03 ; P=0.005)$ and clinical attachment level gain (MD=2.52; $95 \%$ CI 0.96 to $4.09 ; P=0.002$ ). No other statistically significant differences were found.
\end{abstract}


Conclusions: Within the limitations of the present review, the xenograft plus collagen membrane exhibited better periodontal results than spontaneous healing without increasing postoperative complications. However, future welldesigned studies with larger samples are required to confirm our results.

Key words: Third molar, tooth extraction, bone regeneration, xenograft.

\section{Introduction}

Extraction of mandibular third molar (M3M) is a very widespread practice in dentistry. Although its indication is clear when provoking symptoms or disease (e.g. infection, non-restorable caries, periodontal disease, root resorption), currently the prophylactic extraction remains a controversial issue (1). Indeed, the decisionmaking for removal of wisdom teeth has been discussed in the literature and some countries such as Finland, France, The United Kingdom or Spain, have made their own clinical practice guidelines, exhibiting discrepancies between them, especially about the prophylactic extraction of the M3M (2-4).

Periodontal disease on the mandibular second molar (M2M) is one of the primary reasons for the treatment of M3M (5). There are predisposing factors associated to the appearance of bony periodontal defects in the distal aspect of the M2M after the surgical removal of the M3M such as patient's age (older than 25 years), position of the wisdom tooth or pre-existing periodontal defect. Knutsson et al. (6) described that mesioangular or horizontal M3M with a large contact with M2M had a greater risk of periodontal postoperative complications. Additionally, other studies have shown that the surgery itself can also cause a residual intrabony defect behind the M2M (7-9).

To prevent periodontal defects after the M3M extraction, various treatment modalities have been suggested, including different flap designs, soft-tissue suturing, and different bone and tissue regeneration techniques. In the context of periodontal regeneration therapy, bone substitutes such as autologous bone, al- lografts, xenografts or alloplastic grafts and occlusive membranes have been broadly studied $(10,11)$. Each material is associated with some advantages and disadvantages, so their selection should depend on the clinical scenario, as well as, the preferences of the clinician and the patient (12).

Among these bone substitutes, the xenograft has been widely used in the field of bone reconstruction since it is a safe and a well-documented osteoconductive material with a low resorption rate. Due to its chemical composition and its trabecular structure, the xenograft has proven to be a good scaffold for cell growth, and thus, for bone regeneration $(13,14)$.

Despite previous systematic reviews have been published on this topic, none of them compared solely the xenograft to the spontaneous healing. Thus, the aim of the present systematic review and meta-analysis was to gather the published randomized clinical trials to determine whether bone regeneration with xenograft is useful to prevent periodontal defects in the distal aspect of the M2Ms after the surgical extraction of the M3M.

\section{Material and Methods}

This systematic review and meta-analysis was conducted in accordance with the statements of "Preferred Reporting Items for Systematic Reviews and Meta-Analyses" (PRISMA) (15).

- Eligibility criteria

The inclusion criteria were depicted in Table 1. We included articles that met the following eligibility criteria: (P) Population: Non-smokers and healthy patients that underwent a M3M extraction.

Table 1: PICOS items. P; population, I; intervention, C; comparison, O; outcomes, S; study design.

\begin{tabular}{|l|l|}
\hline Population & Healthy patients who underwent a M3M extraction \\
\hline Intervention & Bone regeneration with xenograft \\
\hline Comparison & Spontaneous healing \\
\hline \multirow{4}{*}{ Outcomes } & Periodontal parameters registered on the distal site of the M2M \\
\cline { 2 - 3 } & - PPD changes \\
\cline { 2 - 3 } & - CAL changes \\
\cline { 2 - 3 } & - ABL changes \\
\cline { 2 - 3 } & - Adverse events \\
\hline Study design & RCTs with at least 6 months follow-up. \\
\hline
\end{tabular}

Abbreviations: ABL; Alveolar bone level, CAL; Clinical attachment level, M2M; Mandibular second molar, M3M; Mandibular third molar, PPD; Periodontal probing depth, RCTs; Randomized clinical trials, SRP; Scaling and root planning. 
(I) Intervention: Bone regeneration using bovine xenograft with or without membrane.

(C) Comparison: Spontaneous healing.

(O) Outcomes: Periodontal parameters evaluated on the distal site of the M2M. We registered the periodontal probing depth (PPD), the clinical attachment level (CAL), the alveolar bone level (ABL) the number of adverse events.

(S) Study design: Randomized clinical trials (RCTs) with at least 6 months follow-up. We did not apply any restriction in terms of language and year of publication. According to these PICOS question, we designed the following clinical question: In non-smoker and healthy patients who need the removal of the M3M, what benefit does the use of bone regeneration with xenograft in terms of PPD, CAL, ABL and adverse events when compared to spontaneous healing have?

- Search strategy

Applying the following search strategy: ("molar, third" [MH] OR third molar* [TIAB] OR wisdom teeth* [TIAB] OR wisdom tooth* [TIAB] OR 3rd molar* [TIAB]) AND ("tooth extraction" [MH] OR extraction* [TIAB] OR removal* [TIAB] OR exodontia* [TIAB]) AND ("regeneration" $[\mathrm{MH}] \mathrm{OR}$ "wound healing" $[\mathrm{MH}]$ OR "guided tissue regeneration, periodontal" $[\mathrm{MH}] \mathrm{OR}$ "bone substitutes" $[\mathrm{MH}]$ OR guided bone regeneration* [TIAB] OR xenograft* [TIAB] OR "membranes, artificial" [MH] OR membrane* [TIAB] OR barrier* [TIAB]) NOT ("platelet rich fibrin"), Pubmed, Scopus and Cochrane Library databases were searched by two independent investigators (V.R-R. and J.T-S.) in April 2020. Additionally, we carried out a manual search of articles published during the last 10 years in "Medicina Oral Patología Oral y Cirugía Bucal", "Journal of Oral and Maxillofacial Surgery", "International Journal of Oral and Maxillofacial Surgery", "Journal of Clinical Periodontology", "Journal of Periodontology", "Clinical Oral Investigations", "Oral Surgery Oral Medicine Oral Pathology Oral Radiology", "Journal of Dentistry" and "Journal of the American Dental Association".

- Selection of studies

Two independent reviewers (V.R-R. and J.T-S.) carried out the selection of studies. After we removed the duplicates and the articles based on their title and abstracts, we selected the papers according to the inclusion criteria. Cohen's kappa statistic was computed to measure the level of agreement between the two investigators.

Any disagreement during the article selection was resolved thanks to one independent investigator (MÁ.S-G.).

- Data extraction

The data extraction process was performed by two independent researchers (V.R-R. and J.T-S.). The extraction tables included the name of the authors, country of origin, year of publication, study design, participant characteristics, surgical interventions, postoperative follow-up and the outcomes. Finally, we contacted with the authors of the selected studies for clarification when data were missing or incomplete.

- Risk of bias assessment

Two independent reviewers (V.R-R. and J.T-S.) evaluated the risk of bias of each article by means of "Cochrane Handbook for systematic reviews of interventions, version 5.1.0" (16). We evaluated as low, unclear or high risk of bias the following six quality criteria: random sequence generation, allocation concealment, patient blinding, outcome blinding, incomplete outcome data and selective reporting. Finally, a third independent reviewer (MÁ.S-G.) resolved any disagreement during this step.

- Statistical analysis

Odds ratio (OR) with $95 \%$ confidence intervals (CI) was used for adverse events outcome. In order to estimate the size of the effect, mean difference (MD) and standard deviation (SD) were used for PPD, CAL and ABL. A pairwise meta-analysis was conducted using RevMan software (Review Manager version 5.3; The Cochrane Collaboration, Copenhagen, Denmark) using M3M as the statistical unit in split-mouth studies. We selected the random effect model due to methodological and clinical heterogeneity expected across the included studies (17). In addition, significant heterogeneity was interpreted when I 2 value was $>50$ (18). Statistical significance was defined as $\mathrm{P}<0.05$ for all analyses.

\section{Results}

- Study selection and description

The initial electronic and manual search rendered 795 references. After the removal of the duplicates and the irrelevant articles based on their title and abstracts, 7 full texts were screened. Inter-reviewer agreement between the investigators (V.R-R. and J.T-S.) was $100 \%$ with a Cohen's kappa index of 1 (perfect agreement).

The reasons for rejecting four articles were as follows: an insufficient follow-up (19), duplicates studies $(20,21)$ and included smoker patients (22). Finally, for the present review three articles (23-25) were selected (Fig. 1).

- Risk of bias assessment

As shown on Fig. 2, one article had a low risk of bias (25), while the studies published by Hassan et al. (24) and Andrade-Munhoz et al. (23) were classified as having unclear and high risk of bias, respectively.

- Extraction Data

We pooled the results of three articles (23-25) for assessing the xenograft alone or the xenograft covered by a collagen membrane after the removal of the M3M. The selected studies had a split-mouth design that comprised 98 patients (17 dropouts). Finally, this systematic review involves 81 patients with $162 \mathrm{M} 3 \mathrm{Ms}$ were included for the qualitative and quantitative analysis (Table 2). 
Table 2: Description of the selected studies.

\begin{tabular}{|c|c|c|c|}
\hline Authors & Andrade-Munhoz et al. (23) & Hassan et al. (24) & Sammartino et al. (25) \\
\hline Year & 2011 & 2012 & 2009 \\
\hline Country & Brazil & Saudi Arabia & Italy \\
\hline Study design & $\begin{array}{l}\text { Randomized clinical trial } \\
\text { (Split mouth design) }\end{array}$ & $\begin{array}{l}\text { Randomized clinical trial } \\
\text { (Split mouth design) }\end{array}$ & $\begin{array}{l}\text { Randomized clinical trial } \\
\text { (Split mouth design) }\end{array}$ \\
\hline Population & $\begin{array}{l}\text { Non-smokers and healthy } \\
\text { patients with impacted M3M } \\
\text { symmetrically positioned }\end{array}$ & $\begin{array}{l}\text { Non-smokers and healthy pa- } \\
\text { tients with bilateral and hori- } \\
\text { zontal impacted M3M }\end{array}$ & $\begin{array}{l}\text { Non-smokers and healthy patients } \\
\text { with bilateral and mesioangular or } \\
\text { horizontal impacted M3Ms. } \\
\text { Participants were included if authors } \\
\text { recorded before the surgery a PPD } \\
\text { >or }=7 \mathrm{~mm} \text { and CAL }>\text { or }=6 \mathrm{~mm} \text { in the } \\
\text { distal site of the M2M. }\end{array}$ \\
\hline \multirow[t]{2}{*}{ Intervention } & \multirow{2}{*}{$\begin{array}{c}\text { Xenograft } \\
+ \\
\text { Collagen membrane }\end{array}$} & \multirow[t]{2}{*}{$\begin{array}{c}\text { Xenograft } \\
+ \\
\text { Collagen membrane }\end{array}$} & $\begin{array}{c}\text { Xenograft } \\
+ \\
\text { Collagen membrane }\end{array}$ \\
\hline & & & Xenograft \\
\hline Comparison & Spontaneous healing & Spontaneous healing & Spontaneous healing \\
\hline Follow-up (months) & 24 & 12 & 72 \\
\hline
\end{tabular}

Abbreviations: ABL; Alveolar bone level, CAL; Clinical attachment level, CM; Collagen membrane, M2M; Mandibular second molar, M3M; Mandibular third molar, PPD; Periodontal probing depth, SRP; Scaling and root planning.

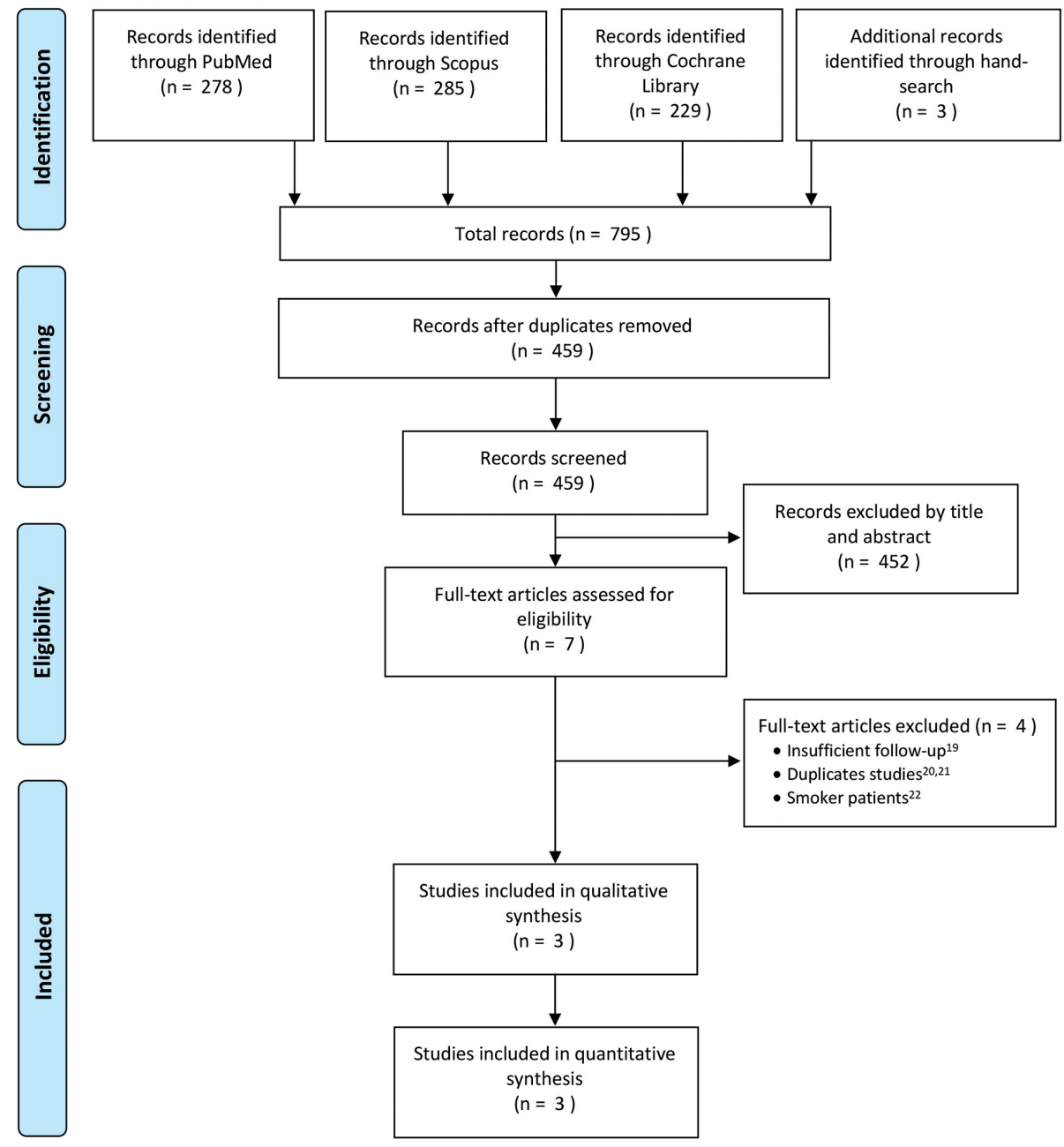

Fig. 1: PRISMA flow chart of the study selection process. 


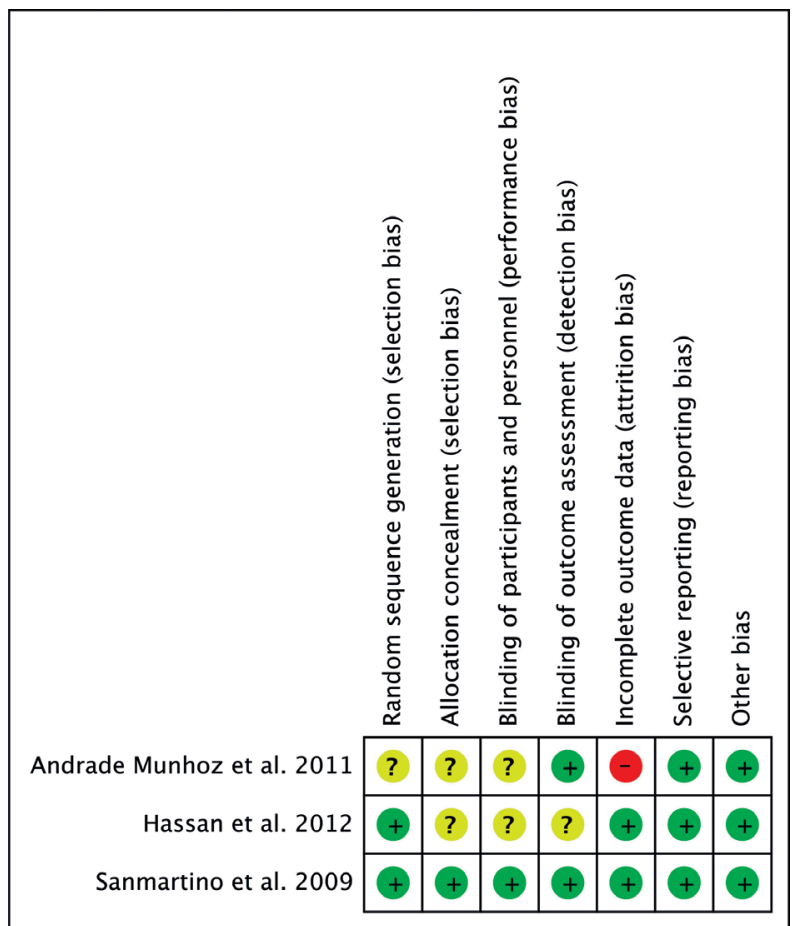

Fig. 2: The Cochrane Collaboration's tool for assessing risk of bias for randomized controlled trials.

- Qualitative synthesis

Across the three included trials in the present review (23-25), one of these studies had a multi-arm design (25). All included papers compared xenograft plus collagen membrane versus spontaneous healing (23-25), while the multi-arm study had also a group comparing the xenograft without membrane (25).

In two trials $(24,25)$, the xenograft covered or not by a collagen membrane revealed a statistically greater PPD and CAL gain than spontaneous healing at 12 months of follow-up after the M3M extraction $(\mathrm{P}<0.05)$.

Regarding ABL gain, one paper (23) reported higher values comparing xenograft covered by a collagen membrane $(\mathrm{MD}=2.36$; $95 \% \mathrm{CI} 0.69$ to 4.03 ; $\mathrm{P}=0.005)$ and spontaneous healing.

The results of the study by Sammartino et al. (25) showed that the xenograft plus the collagen membrane group had a significantly better results in terms of PPD and CAL than the group that used the xenograft alone $(\mathrm{P}<0.05)$.

None of the papers revealed statistically significant differences between groups with regard to adverse events. Out of the two studies that reported this outcome, three postoperative infections occurred in the grafted group and one in the control group (23).

- Quantitative synthesis

The same studies included in the qualitative synthesis were used to perform a pairwise meta-analysis comparing the use of xenograft covered by a collagen membrane after the removal of the M3M (23-25). We were unable to meta-analyse the adverse events outcome due to lack of data.

The results of two articles $(24,25)$ were pooled for PPD and CAL analysis. These studies involved $73 \mathrm{M} 3 \mathrm{Ms}$ in total. Quantitative analysis favoured the use of the xenograft plus collagen membrane over the spontaneous healing in terms of PPD gain (MD $=2.36 ; 95 \% \mathrm{CI} 0.69$ to 4.03; $\mathrm{P}=0.005 ; \mathrm{I} 2=97 \%$ ) (Fig. 3, Table 3) and $\mathrm{CAL}$ gain $(\mathrm{MD}=2.52 ; 95 \%$ CI 0.96 to $4.09 ; \mathrm{P}=0.002 ; \mathrm{I} 2=95 \%$ ) (Fig. 3 , Table 3). No statistically significant differences were found in terms of ABL changes (Fig. 3, Table 3).

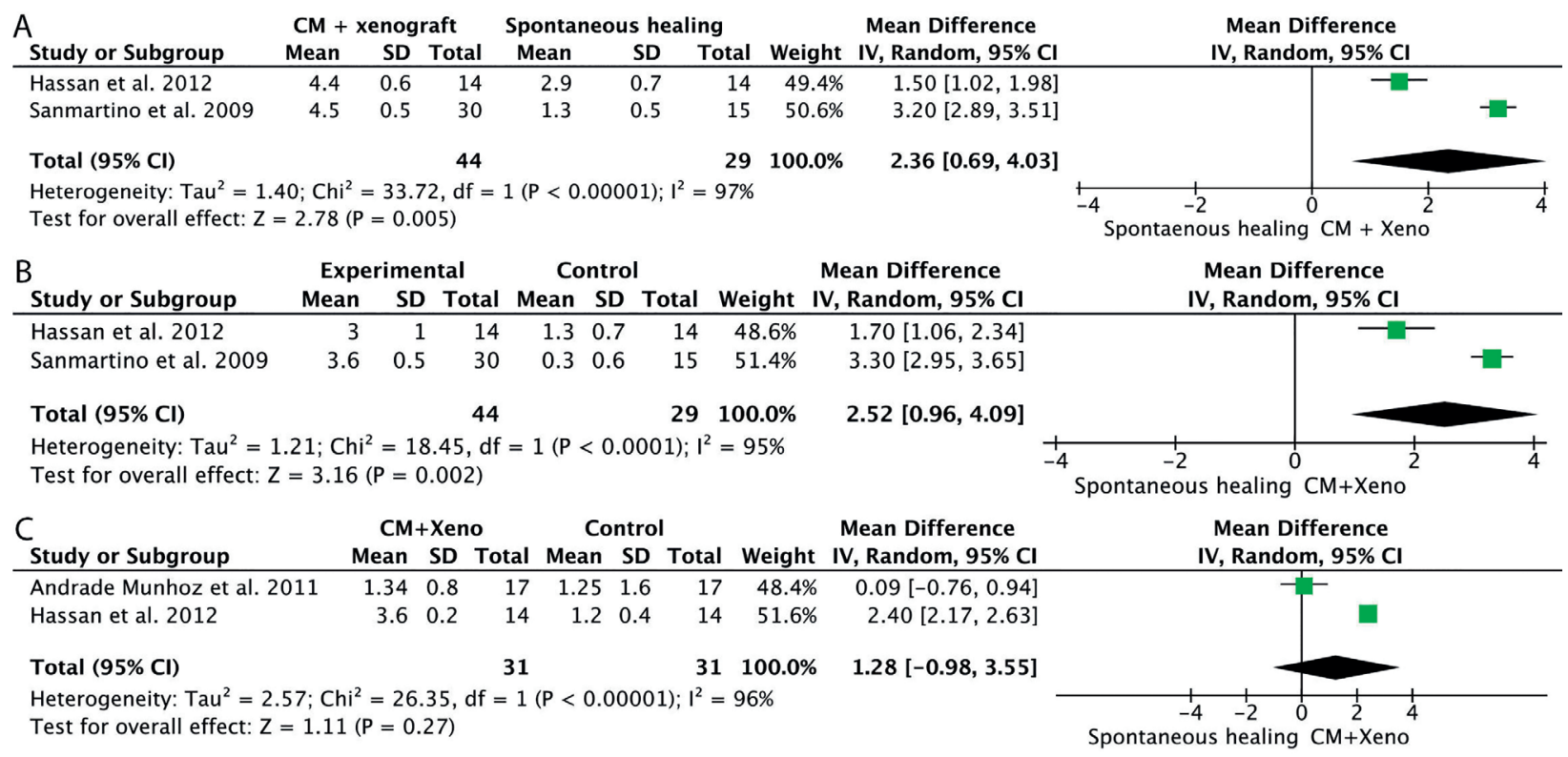

Fig. 3: Forest plots for mean difference of periodontal probing depth reduction (PPD) (A), mean difference of clinical attachment level gain (CAL) (B) and mean difference of alveolar bone level gain (ABL) (C). 
Table 3: Comparison of the selected studies.

\begin{tabular}{|c|c|c|c|c|}
\hline & \multicolumn{4}{|c|}{ Study (year) } \\
\hline & $\begin{array}{l}\text { Andrade-Munhoz } \\
\text { et al. (23) }\end{array}$ & \begin{tabular}{|l|} 
Hassan \\
et al. $(24)$
\end{tabular} & $\begin{array}{c}\text { Sammartino } \\
\text { et al. }(25)\end{array}$ & $\begin{array}{l}\text { Sammartino } \\
\text { et al. (25) }\end{array}$ \\
\hline & $(2011)$ & $(2012)$ & $(2009)$ & $(2009)$ \\
\hline \multicolumn{5}{|l|}{ Intervention } \\
\hline Experimental group & $\begin{array}{c}\text { xenograft }+ \text { collagen } \\
\text { membrane }\end{array}$ & $\begin{array}{c}\text { xenograft }+ \text { collagen } \\
\text { membrane }\end{array}$ & $\begin{array}{c}\text { xenograft }+ \text { collagen } \\
\text { membrane }\end{array}$ & xenograft \\
\hline Control & spontaneous healing & spontaneous healing & spontaneous healing & spontaneous healing \\
\hline \multicolumn{5}{|l|}{$\mathbf{N}^{0}$. patients $\left(\mathrm{N}^{0} \mathrm{M} 3 \mathrm{M}\right)$ (dropouts) } \\
\hline Test & $39(39)(17)$ & $14(14)(0)$ & $15(30)(0)$ & $15(30)(0)$ \\
\hline Control & $39(39)(17)$ & $14(14)(0)$ & $15(15)(0)$ & $15(15)(0)$ \\
\hline \multicolumn{5}{|l|}{ Age of participants, years } \\
\hline Experimental group, (Range) & $15-25$ & $32(2.03)$ & $21-30$ & $21-30$ \\
\hline Spontaneous healing, (Range) & $15-25$ & $32(2.03)$ & $21-30$ & $21-30$ \\
\hline \multicolumn{5}{|l|}{ SRP of distal M2M } \\
\hline Experimental group & Yes & Yes & Yes & Yes \\
\hline Spontaneous healing & Yes & Yes & Yes & Yes \\
\hline Ostectomy & Not reported & Yes & Yes & Yes \\
\hline Socket debridement & Yes & Yes & Yes & Yes \\
\hline \multicolumn{5}{|l|}{ PPD reduction, $\mathrm{mm}$} \\
\hline Experimental group & \multirow{4}{*}{ Not reported } & $4.4(0.6)$ & $4.5(0.5)$ & $3.7(0.2)$ \\
\hline Spontaneous healing & & $2.9(0.7)$ & $1.3(0.5)$ & $1.3(0.5)$ \\
\hline Mean difference $(95 \% \mathrm{CI})$ & & $1.50(1.02,1.98)$ & $3.20(2.89,3.51)$ & $2.40(2.14,2.66)$ \\
\hline$p$ value & & $<0.001^{*}$ & $<0.001^{*}$ & $<0.001^{*}$ \\
\hline \multicolumn{5}{|l|}{ CAL gain, $\mathrm{mm}$} \\
\hline Experimental group & \multirow{4}{*}{ Not reported } & $3.0(1.0)$ & $3.6(0.5)$ & $2.9(0.5)$ \\
\hline Spontaneous healing & & $1.3(0.7)$ & $0.3(0.6)$ & $0.3(0.6)$ \\
\hline Mean difference $(95 \% \mathrm{CI})$ & & $1.70(1.06,2.34)$ & $3.30(2.95,3.65)$ & $2.60(2.25,2.95)$ \\
\hline$p$ value & & $<0.001^{*}$ & $<0.001^{*}$ & $<0.001^{*}$ \\
\hline \multicolumn{5}{|l|}{ ABL gain, mm } \\
\hline Experimental group & $1.34(0.8)$ & $3.6(0.2)$ & \multirow{4}{*}{ Not reported } & \multirow{4}{*}{ Not reported } \\
\hline Spontaneous healing & $1.25(1.6)$ & $1.2(0.4)$ & & \\
\hline Mean difference $(95 \% \mathrm{CI})$ & $0.09(-0.76,0.94)$ & $2.40(2.17,2.63)$ & & \\
\hline$p$ value & 0.8370 & $<0.001^{*}$ & & \\
\hline \multicolumn{5}{|l|}{ Adverse events } \\
\hline Experimental group, $\mathrm{N}^{\mathrm{o}}$ & 3 & 0 & \multirow{4}{*}{ Not reported } & \multirow{4}{*}{ Not reported } \\
\hline Spontaneous healing, $\mathrm{N}^{\mathbf{o}}$ & 1 & 0 & & \\
\hline OR $(95 \% \mathrm{CI})$ & $3.17(0.31,31.86)$ & Not estimable & & \\
\hline$p$ value & 0.328 & Not applicable & & \\
\hline
\end{tabular}

Abbreviations: ABL; Alveolar bone level, CAL; Clinical attachment level, CI; Confidence interval, CM; Collagen membrane, M2M; Mandibular second molar, M3M; Mandibular third molar, OR; Odds ratio, PPD; Periodontal probing depth, SRP; Scaling and root planning.

\section{Discussion}

The purpose of the present study was to answer the following clinical question: in M3M post-extraction sites, what benefit does the use of bone regeneration with xenograft in terms of PPD, CAL, ABL and adverse events when compared to spontaneous healing have? After performing the meta-analysis, our results revealed a significant PPD reduction and CAL gain comparing guided bone regeneration (xenograft plus collagen membrane) versus spontaneous healing. Moreover, the bone filling with xenograft and the spontaneous healing resulted in similar ABL gain and number of postoperative complications.
Periodontal defect in the distal site of the $\mathrm{M} 2 \mathrm{M}$ is a common finding in patients undergoing M3M extraction. In fact, through the selected studies, up to $50 \%$ of the cases exhibited PPD of at least $7 \mathrm{~mm}$ before the intervention $(24,25)$. This resembles the results of Garaas et al. (26) in which $65 \%$ of the patients had a PPD $\geq 4$ $\mathrm{mm}$ at the distal site of the M2M.

The age of patients has their own relevance in bone regeneration of M3M sites. Kugelberg (27) demonstrated that patients older than 25 years old have a poor periodontal healing, which might cause periodontal pockets behind the $\mathrm{M} 2 \mathrm{M}$. In relation to this, the maximum age range of the patients included in our systematic review 
reaches 35 years old with impacted M3Ms, so they could obtain a greater benefit from xenograft bone regeneration to prevent future periodontal defects.

Over the years, different techniques (i.e. incision designs, soft-tissue suturing, scaling and root planning or periodontal regeneration) and materials (i.e. platelet concentrates, bone substitutes or occlusive membranes) have been investigated to solve this problem. A recent meta-analysis published by Chen et al. (28) showed a possible benefit of leaving a portion of gingiva around the M2M during the incision of the M3M extraction. Regarding other bone regeneration biomaterials, the results of this review have shown some discrepancies. Ge et al. (29) did not show significant results in PPD reduction and CAL gain at 6 and 12 months of followup with autologous bone substitute. Another autologous material that, unlike xenograft (23-25), has shown poor results in bone regeneration was platelet rich plasma (PRP), but instead, it has shown an improvement in soft tissue healing $(30,31)$.

On the other hand, regarding the ABL gain, neither allograft $(32,33)$ nor alloplastic (34) biomaterials showed significant improvements which could be in line with xenograft, specifically with the included study by Andrade-Munhoz et al. (23) In contrast, Hassan et al. (24) obtained a significant ABL gain with the use of xenograft at 12 months of follow-up. It should be noted that Andrade-Munhoz et al. (23) used a new type of xenograft that is only marketed in Brazil, unlike the other 2 articles analysed in this systematic review $(24,25)$, which used a type of well-known xenograft, supported by numerous studies.

Regarding the use of resorbable or non-absorbable membrane there are no statistically significant differences between them, however, second surgery is avoided when the resorbable membranes are used $(35,36)$. In this review, only one study (25) compared the xenograft with or without membrane and the best outcomes were for the membrane group.

Generally, bone regeneration increases the risk of postoperative complications $(29,32,34)$, however, among the included studies, we did not obtain significant complications (23).

Although it would be interesting to obtain histological studies to observe whether tissue regeneration is formed, it is not clinically relevant since the objective of bone regeneration is that the patients do not have periodontal defects, being able to maintain stable over time. Across the included studies, only one of them (25) provided histological results showing that with the use of a collagen membrane the level of xenogeneic particles was lower and more mature osteoid matrix (better bone quality) was observed at 6 months. Nevertheless, it is not essential since we have not evaluated this outcome. In this review, all included studies (23-25) performed a scaling and root planning either in experimental or control groups. This procedure has been shown to remove plaque and calculus behind M2M and it consequently improves periodontal healing (37) therefore, the included studies could have been benefited from this procedure.

There were several limitations related to the present study that must be mentioned. Firstly, only three papers which compared the guided bone regeneration with xenograft and the spontaneous healing were able to be included in our meta-analysis. There were no studies to compare by a meta-analysis the effectiveness of the xenograft without a collagen membrane. Moreover, the limited number of patients and M3M included together with the fact that only one paper of the selected studies had a low risk of bias, did not allow to make robust conclusions. Another possible drawback of this metaanalysis was the substantial heterogeneity across the selected studies. Thus, authors recommend being cautious with the results of the present review.

\section{Conclusions}

Within the above-mentioned limitations, it can be concluded that guided bone regeneration with xenograft and collagen membrane exhibited greater PPD reduction and CAL gain in the distal aspect of the M2M after the surgical extraction of the M3M than spontaneous healing. However, to confirm our results well-conducted investigations with larger samples and with a longer follow-up are needed.

\section{References}

1. Steed MB. The indications for third-molar extractions. J Am Dent Assoc. 2014;145:570-3.

2. McArdle LW, Renton T. The effects of NICE guidelines on the management of third molar teeth. Br Dent J. 2012;213:E8.

3. French Society of Stomatology, Maxillo-Facial Surgery and Oral Surgery (SFSCMFCO). French good practice guidelines regarding third molar removal: Indications, techniques, methods. J Stomatol Oral Maxillofac Surg. 2020; [published online ahead of print].

4. Ghaeminia H, Nienhuijs ME, Toedtling V, Perry J, Tummers M, Hoppenreijs TJ, et al. Surgical removal versus retention for the management of asymptomatic disease-free impacted wisdom teeth. Cochrane Database Syst Rev. 2020;5:CD003879.

5. Venta I, Ylipaavalniemi P, Turtola L. Long-term evaluation of estimates of need for third molar removal. J Oral Maxillofac Surg. 2000;58:288-91

6. Knutsson K, Brehmer B, Lysell L, Rohlin M. Pathoses associated with mandibular third molars subjected to removal. Oral Surg Oral Med Oral Pathol Oral Radiol Endod. 1996;82:10-7.

7. Kugelberg CF, Ahlström U, Ericson S, Hugoson A, Thilander H. The influence of anatomical, pathophysiological and other factors on periodontal healing after impacted lower third molar surgery. A multiple regression analysis. J Clin Periodontol. 1991;18:37-43.

8. Montero J, Mazzaglia G. Effect of removing an impacted mandibular third molar on the periodontal status of the mandibular second molar. J Oral Maxillofac Surg. 2011;69:2691-7.

9. Peng KY, Tseng YC, Shen EC, Chiu SC, Fu E, Huang YW. Mandibular second molar periodontal status after third molar extraction. J Periodontol. 2001;72:1647-51.

10. Camps-Font O, Caro-Bonfill C, Sánchez-Garcés MÀ, Gay-Esco- 
da C. Periodontal regenerative therapy for preventing bone defects distal to mandibular second molars after surgical removal of impacted third molars: A systematic review and meta-analysis of randomized clinical trials. J Oral Maxillofac Surg. 2018;76:2482-514.

11. Lee CT, Hum L, Chen YW. The effect of regenerative periodontal therapy in preventing periodontal defects after the extraction of third molars: A systematic review and meta-analysis. J Am Dent Assoc. 2016;147:709-19.

12. Bucchi C, Del Fabbro M, Arias A, Fuentes R, Mendes JM, Ordonneau M, et al. Multicenter study of patients' preferences and concerns regarding the origin of bone grafts utilized in dentistry. Patient Prefer Adherence. 2019;13:179-85.

13. Sogal A, Tofe AJ. Risk assessment of bovine spongiform encephalopathy transmission through bone graft material derived from bovine bone used for dental applications. J Periodontol. 1999;70:1053-63. 14. Sheikh Z, Hamdan N, Ikeda Y, Grynpas M, Ganss B, Glogauer M. Natural graft tissues and synthetic biomaterials for periodontal and alveolar bone reconstructive applications: A review. Biomater Res. 2017;21:1-20.

15. Moher D, Shamseer L, Clarke M, Ghersi D, Liberati A, Petticrew $\mathrm{M}$, et al. Preferred reporting items for systematic review and metaanalysis protocols (PRISMA-P) 2015 statement. Syst Rev. 2015;4:1-9. 16. Cumpston M, Li T, Page MJ, Chandler J, Welch VA, Higgins JP, et al. Updated guidance for trusted systematic reviews: A new edition of the Cochrane Handbook for Systematic Reviews of Interventions. Cochrane Database Syst Rev. 2019;10:ED000142.

17. DerSimonian R, Laird N. Meta-analysis in clinical trials. Control Clin Trials. 1986;7:177-88.

18. Higgins JPT, Thompson SG. Quantifying heterogeneity in a meta-analysis. Stat Med. 2002;21:1539-58.

19. de Melo D, de Santana Santos T, Sehn F, de Oliveira e Silva E, Martins-Filho PS, Dourado ACG. Evaluation of inorganic bovine bone graft in periodontal defects after third molar surgery. Ann Maxillofac Surg. 2015;5:198-202.

20. Ferreira Júnior O, Munhoz EA, Segantin JF, Gonçales ES, Carvalho $\mathrm{P}$. Tomographic late evaluation of xenogeneic bone grafts in sockets of impacted third molars. J Appl Oral Sci. 2018;26:e20170396. 21. Munhoz EA, Ferreira O, Yaedu RY, Granjeiro JM. Radiographic assessment of impacted mandibular third molar sockets filled with composite xenogenic bone graft. Dentomaxillofac Radiol. 2006;35:371-5

22. Oliveira MN, Rau LH, Marodin A, Corrêa M, Corrêa LR, Aragones A, et al. Ridge preservation after maxillary third molar extraction using $30 \%$ porosity PLGA/HA/ $\beta$-TCP scaffolds with and without simvastatin: A pilot randomized controlled clinical trial. Implant Dent. 2017;26:832-40.

23. Andrade Munhoz E, Bodanezi A, Junior OF, Granjeiro JM. Bone crestal height and bone density after third-molar extraction and grafting: A long-term follow-up study. Clin Oral Investig. 2011;15:123-6. 24. Hassan KS, Marei HF, Alagl AS. Does grafting of third molar extraction sockets enhance periodontal measures in 30- to 35-yearold patients?. J Oral Maxillofac Surg. 2012;70:757-64.

25. Sammartino G, Tia M, Bucci T, Wang HL. Prevention of mandibular third molar extraction-associated periodontal defects: A comparative study. J Periodontol. 2009;80:389-96.

26. Garaas RN, Fisher EL, Wilson GH, Phillips C, Shugars DA, Blakey GH, et al. Prevalence of third molars with caries experience or periodontal pathology in young adults. J Oral Maxillofac Surg. 2012;70:507-13.

27. Kugelberg CF. Periodontal healing two and four years after impacted lower third molar surgery. Int J Oral Maxillofac Surg. 1990;19:341-5.

28. Chen YW, Lee CT, Hum L, Chuang SK. Effect of flap design on periodontal healing after impacted third molar extraction: A systematic review and meta-analysis. Int J Oral Maxillofac Surg. 2017;46:363-72.

29. Ge J, Yang C, Zheng J, Hu Y. Autogenous bone grafting for treatment of osseous defect after impacted mandibular third molar extraction: A randomized controlled trial. Clin Implant Dent Relat Res. 2017;19:572-80.
30. Sammartino G, Tia M, Marenzi G, Espedito Di Lauro A, D'Agostino E, Claudio PP. Use of autologous Platelet-Rich Plasma (PRP) in periodontal defect treatment after extraction of impacted mandibular third molars. J Oral Maxillofac Surg. 2005;63:766-70.

31. Kaul RP, Godhi SS, Singh A. Autologous platelet rich plasma after third molar surgery: A comparative Study. J Maxillofac Oral Surg. 2012;11:200-5.

32. Dodson TB. Management of mandibular third molar extraction sites to prevent periodontal defects. J Oral Maxillofac Surg. 2004;62:1213-24.

33. Tabrizi R, Khorshidi H, Shahidi S, Gholami M, Kalbasi S, Khayati A. Use of lincomycin-impregnated demineralized freezedried bone allograft in the periodontal defect after third molar surgery. J Oral Maxillofac Surg. 2014;72:850-7.

34. Throndson RR, Sexton SB. Grafting mandibular third molar extraction sites: A comparison of bioactive glass to a nongrafted site. Oral Surg Oral Med Oral Pathol Oral Radiol Endod. 2002;94:413-9. 35. Corinaldesi G, Lizio G, Badiali G, Morselli-Labate AM, Marchetti C. Treatment of intrabony defects after impacted mandibular third molar removal with bioabsorbable and non-resorbable membranes. J Periodontol. 2011;82:1404-13.

36. Oxford GE. Treatment of 3rd molar-induced periodontal defects with guided tissue regeneration. J Clin Periodontol. 1997;24:464-9. 37. Leung WK, Corbet EF, Kan KW, Lo ECM, Liu JK. A regimen of systematic periodontal care after removal of impacted mandibular third molars manages periodontal pockets associated with the mandibular second molars. J Clin Periodontol. 2005;32:725-31.

\section{Funding}

This research did not receive any specific grant from funding agencies in the public, commercial, or not-for-profit sectors.

\section{Conflict of interest}

The authors declare that there are no conflicts of interest regarding the present study. The authors would like to declare the following interests outside the work presented:

The authors Jorge Toledano-Serrabona, Victor Romero-Ruiz and Prof. $\mathrm{M}^{\mathrm{a}}$ Ángeles Sánchez-Garcés have received no grants, personal fees or non-financial support.

Octavi Camps-Font has participated as a sub-investigator in clinical trials sponsored by Mundipharma (Cambridge, UK) and Menarini Richerche (Florence, Italy).

Prof. Cosme Gay-Escoda has participated as a principal investigator in several randomized clinical trials sponsored by Mundipharma (Cambridge, UK) and Menarini Richerche (Florence, Italy).

\section{Authors contributions}

Jorge Toledano-Serrabona: Acquisition, analysis and interpretation of the data, drafting of the article; approval of the final version of the manuscript and agreement to be accountable for all aspects of the work.

Víctor Ruiz-Romero: Conception and design of the study; acquisition, analysis and interpretation of the data; drafting of the article; agreement to be accountable for all aspects of the work.

Octavi Camps-Font: Critical revision of the manuscript; approval of the final version of the manuscript and agreement to be accountable for all aspects of the work.

Cosme Gay-Escoda: Critical revision of the manuscript; approval of the final version of the manuscript and agreement to be accountable for all aspects of the work.

M Ángeles Sánchez-Garcés: Conception and design of the study; interpretation of the data; drafting of the article; critical revision of the manuscript, approval of the final version of the manuscript and agreement to be accountable for all aspects of the work. 